\title{
¿El declive del significado social de la música?
}

The Decline in the Social Significance of Music?

Le déclin de la signification sociale de la musique?

Ion Andoni del Amo, Arkaitz Letamendia y Jason Diaux

\section{OpenEdition}

\section{Journals}

Edición electrónica

URL: http://journals.openedition.org/rccs/6189

DOI: $10.4000 /$ rccs. 6189

ISSN: 2182-7435

\section{Editor}

Centro de Estudos Sociais da Universidade de Coimbra

\section{Edición impresa}

Fecha de publicación: 1 mayo 2016

Paginación: 11-32

ISSN: 0254-1106

\section{Referencia electrónica}

Ion Andoni del Amo, Arkaitz Letamendia y Jason Diaux, « ¿El declive del significado social de la música? », Revista Crítica de Ciências Sociais [En línea], 109 | 2016, Puesto en línea el 18 mayo 2016, consultado el 19 abril 2019. URL : http://journals.openedition.org/rccs/6189; DOI : 10.4000/ rccs.6189 


\title{
ION ANDONI DEL AMO, ARKAITZ LETAMENDIA, JASON DIAUX
}

\section{¿El declive del significado social de la música?}

\begin{abstract}
¿Nos encontramos ante un declive del significado social de la música? Por un lado las innovaciones tecnológicas, especialmente la digitalización, modifican las formas sociales de acceso a la música, con un progresivo aumento de disposiciones más individuales que no requieren redes personales cara a cara -las cuales potenciaban la construcción identitaria alrededor de la música. Por otra parte, la lógica del mercado cultural global, del usar y tirar, impacta en la música, disminuyendo su capacidad de proveer significado social e identidad. Como resultado, planteamos que el "declive" se refiere a un cambio en el significado social de la música, pasando de ser un elemento de construcción identitaria hacia uno de socialidad comunicativa. Hoy en día su principal función es la de compartir, proveyendo un lenguaje común para la socialidad, donde las neotribus se disuelven.
\end{abstract}

Palabras clave: consumo musical; evolución tecnológica; globalización; música e identidad; sociología de la música.

Palavras-chave: consumo musical; evolução tecnológica; globalização; música e identidade; sociologia da música.

\section{Introducción}

En este artículo abordamos la cuestión de si en la actualidad el significado social de la música se encuentra en decadencia; es decir, si con la irrupción de las redes telemáticas la capacidad de articular identidades sociales alrededor de la música se ha debilitado. Nuestra hipótesis apunta a que, en un contexto de intrusión de las redes sociales y de la lógica del mercado del capitalismo tardío en diversos campos culturales semiautónomos como el musical (Bourdieu, 2001), efectivamente la música pierde parte de su capacidad de construir identidades a su alrededor. Sin embargo, en la otra cara de la moneda, mediante Internet y el conjunto de redes telemáticas, nos encontramos con un mayor potencial de difusión masiva de la producción musical y un énfasis en la socialidad comunicativa de la misma, si bien en torno a los productos más mainstream. 
Para dar a conocer estas ideas, dividimos el artículo en tres partes. En una primera parte desarrollamos el marco teórico y presentamos los debates académicos existentes respecto a la música y su papel social. En este punto, tras realizar un breve repaso a los principales autores y posiciones existentes -especialmente las subculturalistas y postsubculturalistas-, tratamos de determinar cuál es la idea del significado social de la música en el que nos apoyamos. En una segunda parte planteamos un análisis del contexto, y para ello profundizamos en los potenciales procesos de vaciado y estetización de la cultura contemporánea, que varios autores críticos con las consecuencias sociales del posmodernismo plantean (Harvey, 1998; Jameson, 1998).

Una vez establecidas estas bases teóricas, en una tercera parte proponemos un análisis empírico, basado en técnicas cualitativas. La investigación etnográfica que aquí plateamos se centra en músicas populares urbanas en el contexto de Euskal Herria (Pais Vasco), donde la música ha jugado un papel significativo en las últimas décadas a la hora de movilizar afectos y emociones (Amezaga, 1995; Gabilondo, 2009; Larrinaga, 2014). En todo caso, consideramos que sus implicaciones teóricas podrían aplicarse igualmente a otros contextos, al menos a otros países del mundo occidental.

En concreto, en este estudio analizamos extractos de entrevistas que consideramos representativas, seleccionadas de una muestra total de 43. Distinguimos tres tipologías básicas de entrevistados, que no son sino los actores principales en la escena musical y cultural: músicos (22 entrevistas), programadores (10) y expertos, principalmente periodistas musicales o pensadores y activistas culturales (11). Con respecto a la periodización, las entrevistas se han realizado entre septiembre de 2013 y septiembre de 2014.

Finalmente, exponemos las conclusiones del trabajo. Así, a partir de las bases teóricas establecidas y las entrevistas realizadas, interpretamos la hipótesis sobre el declive del significado social de la música contemporánea, como elemento de construcción de identidad, y su paso hacia la socialidad comunicativa.

\section{El significado de la música y el estilo}

Un largo y fructífero debate teórico, sobre todo anglosajón, ha deliberado en las últimas décadas acerca del significado social de la música y el estilo. Su origen son los trabajos clásicos del Centre for Contemporary Cultural Studies (CCCS) de Birmingham (Hall, Cohen, Clarke, Willis o Hebdige).

El CCCS reinsertó la clase social en el corazón del análisis cultural. Politizó el estilo de la juventud de clase trabajadora británica (principalmente blanca, masculina y heterosexual), situando la clase social, antes que la edad 
o generación, en el centro de la teoría. Trataba así de entender cómo la juventud de clase trabajadora reproduce, negocia y transforma sus condiciones materiales a través de prácticas culturales. Lo hacían a través de las lentes de las subculturas, analizadas como "doble articulación", de un lado con la cultura de clase trabajadora de sus padres y, de otro, con la cultura dominante de la cambiante sociedad británica después de la guerra (Hall y Jefferson, 2006; Hebdige, 2004; Hesmondhalgh, 2005).

El concepto de subcultura desarrollado en los trabajos del CCCS fue objeto en los 90 de una crítica sostenida desde otros marcos teóricos, agrupados bajo la etiqueta de postsubculturalistas y situados en la ola del postmodernismo, que frente a la primacía otorgada a la clase social, apuntaban la emergencia de nuevas formas culturales como la "cultura de club" o las ciberculturas (Bennett, 2011; Bennett y Kahn-Harris, 2004; Muggleton, 2010; Thornton, 1995). El punto de vista general es que la creciente importancia del consumo (frente a la producción) ha llevado a una situación donde jóvenes de diferentes antecedentes sociales pueden sostener similares valores que encuentran su expresión en la pertenencia compartida a una subcultura particular. Aún más, las identidades juveniles - y por extensión las identidades sociales per se - se habrían vuelto más reflexivas, fluidas y fragmentadas debido a un creciente flujo de mercancías culturales, imágenes y textos a través de los cuales proyectos de identidad individualizados podrían ser 'fashionados'.

La crítica más extendida hacia la teoría postsubcultural apunta que ésta adopta una ingenua, y esencialmente celebratoria posición con respecto al papel de las industrias culturales en la formación de las identidades y los estilos de vida. La teoría postsubcultural, con su énfasis en el consumo como práctica cultural clave, adoptaría una postura esencialmente complaciente que dibuja una juventud que se deja llevar en un supermercado del estilo, reduciendo la sensibilidad estilística de los jóvenes a poco más que un juego de picar y mezclar, a una suerte de dandismo postmoderno (Blackmann, 2005; Griffin, 2010; Hall y Jefferson, 2006; Hesmondhalgh, 2005; Shildrick y MacDonald, 2006).

$\mathrm{Al}$ ámbito anglosajón se suman también importantes aportaciones como los estudios culturales y de la comunicación latinoamericanos (García Canclini et al., 2012; Martín-Barbero, 1993), las del catalán Carles Feixa (Feixa, 1998; Feixa y Nofre, 2012), o recientes trabajos en lengua portuguesa (Guerra, $2010,2014)$. En todo caso, el debate en torno al concepto de subcultura y las propuestas de superación de éste resulta central, porque en él se condensan varios conceptos: juventud, música, identidad, postmodernidad, política, hegemonía, (contra)cultura, resistencias, clase, género, espacio público... 
Griffin (2010), recogiendo las reflexiones de Hall y Jefferson (2006) con motivo de la reedición de Resistance Through Rituals, defiende lo que considera el principal legado del proyecto subcultural: el desarrollo de una lectura sintomática, situada en el marco de un análisis coyuntural, que permite interpretar no sólo las culturas juveniles y sus consumos culturales (y musicales) asociados, sino a través de ellas leer también los cambios sociales en curso, el papel actual de la cultura, y el significado político de determinadas prácticas culturales.

\section{Estetización y vaciado de la cultura}

Fruto del tiempo de las batallas culturales y la politización de las identidades, especialmente en los 60, y de los cambios del capitalismo, el modo en el que la lógica cultural hegemónica construye su mediación va a mutar con los cambios de la década de los 70. Aparecen las formas culturales posmodernistas, en paralelo a modos más flexibles de acumulación del capital (Harvey, 1998; Jameson, 1998). El marco cultural dominante ahora cubre las diferencias en base a su exhibición y aceptación plural, incluso en la potenciación de lo extraño, y en su realización mercantil en una pretendida construcción "libre" y cambiante de las identidades en una suerte de supermercado cultural global.

Existe en esa formulación de construcción identitaria una interpelación ideológica de fondo, denunciada desde los estudios críticos del consumo (Alonso y Conde, 1994) y la identidad (Azkarraga, 2011), cuya aceptación acrítica será una de las líneas principales de crítica a los trabajos de los postsubculturalistas, que reflejan estas transformaciones (Guerra, 2010; Hesmondhalgh, 2005). La figura del supermercado cultural postmoderno ignora que no todos los individuos están en condiciones de comprar en él -las estructuras socialesy que la experiencia local, los conflictos y las redes de relaciones tienen un peso importante en el proceso de construcción identitaria, que no resulta ni tan "libre" ni tan personalizable.

Es necesario, por tanto, relativizar esas descripciones. Pero, si bien puede que nunca tuvieran tanta como algunas teorizaciones pretendían, quizás además estén perdiendo importancia en los procesos identitarios. Bourdieu (2001), ya alertaba de forma crítica sobre la intrusión en la era neoliberal de la lógica comercial en todos los estadios de la producción cultural, amenazando la independencia y semiautonomía de los diferentes campos culturales. La propia lógica del mercado cultural global, de picar y mezclar, usar y tirar, y el relativismo absoluto del discurso postmoderno, acaba por convertir en insulsos los productos culturales, incapaces de proporcionar sentido e identidad, por líquida que sea.

El pinchazo de la infraestructura económica del capitalismo tardío deja tambaleándose definitivamente a su lógica cultural, y con ella al ejercicio 
mediador de la cultura. La cultura deja de ser el campo privilegiado de acción política, comunicativa e identitaria.

\section{The Times They Are A-Changin'}

Los trabajos de los postsubculturalistas incorporaban muchos de los cambios en relación a la música(s), identidad(es) y culturas juveniles: el creciente papel de las industrias culturales, la importancia de los procesos de consumo, la igualación de los valores más allá de las condiciones sociales, la agudización de las tendencias de individualización, una creciente fluidez y fragmentación, el declive económico y social de la clase trabajadora frente a la clase media como particular-universal...

Éstos y otros cambios sociales, económicos, culturales y tecnológicos más recientes que apuntamos inciden también, en función de las condiciones estructurales y coyunturas particulares, en Euskal Herria.

\subsection{Los cambios tecnológicos: Internet, posibilidades y desigualdades}

Sin caer en la concepción funcionalista del vector tecnológico como agencia de cambio, no puede dejarse de señalar la importancia determinante de desarrollos como Internet. Las nuevas tecnologías de la información y comunicación (TIC) han contribuido a cambiar muchas relaciones sociales, en muchos casos acentuando procesos que venían de antes. En el campo de la música su efecto ha supuesto profundas transformaciones (Yúdice, 2002), ya apuntadas tempranamente por Simon Frith (1999). Así ha sido ampliamente reseñado en multitud de entrevistas.

Músicos de distintas escenas, programadores o cronistas coinciden en señalar las posibilidades que ha abierto Internet, especialmente a la hora de difundir distintos trabajos, permitiendo un acceso global (o casi, si tenemos en cuenta la brecha digital):

Los que no somos conocidos, podemos sonar en todo el planeta solo con mandar los temas a emisoras on line, casi todo el mundo (salvo raras excepciones) te pone tus temas, la repercusión es más o menos importante pero puedes sonar, cosa que hace unos años era imposible con emisoras como los 40... (Javi de House, músico Dj, entrevista personal, 08.11.2013)

Un aumento espectacular de posibilidades de lo que Castells (2009) denomina autocomunicación de masas: las posibilidades individuales de transmitir de forma masiva las creaciones propias, musicales o de otro tipo. Es cierto que los filtros siguen existiendo, como el propio Castells recuerda, pero son mucho más laxos, o percibidos como tales, que los que imponían 
los grandes medios de comunicación o la industria discográfica, incluso la independiente.

La música y periodista Elena López Aguirre (entrevista personal, 24.02.2014) nos relata que en el movimiento punk de los 80 "la célula básica de la que nació un cuerpo vestido habitualmente con chupa de cuero claveteada fue la maketa". La maketa, y todos los espacios de comunicación social (fanzines, revistas, pegatinas, pintadas, cómics, radios libres, la propia música, las tiendas de discos, la circulación de casetes grabadas, los conciertos, el estilo...) tienen bastante de autocomunicación de masas, previamente al salto tecnológico de las TIC. Éstas propician que pueda ser más autónoma, individualizada y más masiva, más global.

Ello en teoría facilitaría desarrollar nuevos gustos. Sin embargo, el periodista musical Iker Barandiaran nos advierte de la cara oscura:

Paralelamente, al unir Internet y las plataformas digitales, es fácil grabar un disco, así como difundirlo e intentar darlo a conocer. Pero como eso hace aumentar la oferta, es más difícil destacar entre los demás. Esa criba que antes hacían las discográficas ha desaparecido, para bien y para mal. ${ }^{1}$ (Iker Barandiaran, periodista musical, entrevista personal, 02.03.2014)

Las facilidades para llegar a todo el mundo, para autocomunicar, se diluyen en un mar de sobreinformación (Zallo, 2011). Y aquí surge la paradoja que reconocen muchos de los entrevistados y que constata nuestra observación directa: con muchas más posibilidades de difundir, conocer y desarrollar nuevos gustos, parece producirse el efecto contrario, en casi todos los lugares se escucha cada vez más la misma música.

\subsection{1. ¿Pero es que siguen sonando los mismos?}

Combativo rapero y Dj de electrónica, Maisha apunta que no todos están en condiciones de igualdad. Aunque la red multiplica y mucho las posibilidades de autocomunicar, y bien el acceso puede resultar más o menos libre, la criba sigue existiendo en cuanto a posibilidades de incidencia. Javier Piñango también ratifica que, aunque la producción y difusión resulta más fácil, el poder de determinadas redes sociales (MySpace, Facebook...) mantiene

\footnotetext{
1 "Paraleloki, Interneten eta plataforma digitalen gailuak batuta, erraza da disko bat grabatu eta disko bat egitea, baita zabaldu eta ezagutzera emateko ahalegina ere. Baina horrek eskaintza handitzen duenez, zailagoa da dagoen guztiaren artean nabarmentzea. Lehen diskoetxeek egiten zuten kriba hori desagertu da, onerako eta txarrerako."
} 
vigentes los filtros; continúan los viejos poderes ${ }^{2}$. La desigualdad en los medios de promoción persiste, incluso quizás más acentuada; y las grandes discográficas parecen conservar en esa dimensión un renovado control sobre la promoción de lo que se escucha masivamente, al menos en los locales de ocio y las emisoras de radio tradicional: son sus productos los que inundan cada vez de forma más masiva los locales nocturnos.

Casi todos los programadores y los propios músicos coinciden en señalar que el público demanda especialmente "canciones conocidas", "las famosas". Y en la definición de cuáles son: las clásicas y, especialmente, las que salen en la radiofórmula, donde la presencia de los productos comerciales de la gran industria musical es dominante. Otros estudios, como el de Álvarez Monzonzillo y Calvi (2015), o el realizado desde la Universidad de La Rioja, coinciden: "no todo el mundo escucha lo mismo, pero hay una parte muy significativa que está muy condicionada por lo que se le ofrece, sin implicarse en la búsqueda de alternativas" (Andrés, 2013: 34).

En suma, las TIC refuerzan las posibilidades de autocomunicar, pero la apertura de los filtros de acceso no suprime totalmente el papel dominante de la gran industria musical. Antes bien, lo que parece es transformar sus estrategias y las formas de escucha del público.

\subsection{La explosión de la burbuja discográfica: Del disco al festival, pasando por muchos conciertos}

Elena López Aguirre (entrevista personal, 24.02.2014) recordaba también cómo "ante la falta de respuesta de los sellos discográficos, atrincherados en una posición muy conservadora ante la crisis, los jóvenes de los años 80 comenzaron a crear su propia infraestructura, una escena, alrededor de pequeños grupos de garaje, hardcore o punk-rock, principalmente". Ante los cambios que produjo el desarrollo de las TIC y especialmente Internet, la industria discográfica pareció de nuevo atrincherarse en similares posiciones. Cuando no directamente avariciosas, como acusa Iker Barandiaran a propósito del precio de los CDs.

Así, el Observatorio Vasco de la Cultura (2015), registra una disminución de la dimensión económica de la industria discográfica, entre 2009 y 2013, que pasa de casi 9,7 millones de euros en ingresos a poco más de 5,1. También disminuyen las copias realizadas (de 322835 a 228 925) y el número de discos vendidos (de 469502 a 299 085).

${ }^{2}$ Conferencia "Producción y difusión de músicas no convencionales: estrategias para la segunda década del siglo xxı". Jornadas de gestión y producción cultural ArtBITE. UPV/EHU, Leioa, octubre de 2011. 
Norton, con una dilatada trayectoria musical, desde sus inicios en los 90 con el grupo de punk-rock en euskara EH Sukarra, un salto posterior al pop-rock con Lorelei o Norton Club, y el reciente retorno de EH Sukarra, señala que hoy en día resulta más complicado conseguir grabar un disco. Mikel, del grupo Sexty Sexers, apunta que aunque las posibilidades se han ampliado gracias a las TIC, el músico pequeño se encuentra hoy en día más sólo. Con todo, como señala el periodista musical Julen Azpitarte, la crisis de las discográficas coincidente con la expansión de Internet abre oportunidades para desarrollar pequeños proyectos y para la autogestión.

La estrategia comercial -la burbuja, apunta el periodista musical Álvaro Heras- se desplazó de la batalla perdida de los discos a la promoción de los conciertos (Álvarez Monzonzillo y Calvi, 2015; Fouce, 2009).

\subsubsection{Auge y pinchazo del concierto}

El cambio de milenio registra un sobresaliente auge del formato de concierto, una suerte de "burbuja". La facilidad de acceso a la producción musical en Internet, de forma gratuita aunque perseguida en muchos casos, es un factor a menudo utilizado para explicar el boom de los conciertos. No obstante, como bien sugieren algunos entrevistados, muchas de las veces los conciertos han recurrido a la movilización de grupos de renombre asentados antes que a apuestas nuevas o arriesgadas: el grupo mítico y la motivación del "yo estuve alli”".

La estrategia de la industria musical, pues, parece que se reorientó hacia la promoción de los conciertos, aunque al tiempo atrincherándose también en posiciones conservadoras. Un conservadurismo que también parece darse, quizás por saturación, entre el público asistente:

Entre la gente que acude a conciertos solo un pequeño porcentaje se arriesga a descubrir nuevas bandas. Y eso es curioso, ahora que con Internet podemos saber de antemano lo que nos vamos a encontrar (eligiendo mejor dentro de la amplia oferta). No como antes, que sin Internet, íbamos a conciertos a ciegas sin saber muy bien lo que nos íbamos a encontrar. (Iker Barandiaran, periodista musical, entrevista personal, 02.03.2014) $)^{3}$

Los responsables de la sala Fever subrayan el fabuloso despliegue de salas de conciertos y programación en Bilbao durante la primera década

\footnotetext{
3 "Kontzertuetara joaten direnen portzentai txiki batek arriskatzen du talde berriak deskubritzeko. Eta hori bitxia da, batez ere, orain Internet bidez aurrez zer aurkituko dugun egiaztatzeko (eta horren arabera, eskaintza zabalaren barruan hobeto aukeratzeko) aukera anitzak ditugulako. Ez, lehen bezala. Lehen Internet gabe, ia itsu-itsuan joaten ginen kontzertuak ikustera zer aurkituko genuen jakin gabe."
} 
del siglo xxi, en contraste con el desierto que era la capital anteriormente: "En el año 93 estaba el gaztetxe ${ }^{4}$ y nada más". "Las bandas empiezan a pasar por aquí" (Programadores musicales Sala Fever, entrevista personal, 08.10.2013).

Con todo, Julen Azpitarte señala el progresivo encarecimiento del formato concierto: a la propia entrada hay que sumar el precio nada desdeñable de las bebidas en los locales. Muchos conciertos llegan a adquirir cierto carácter elitista. Aunque en locales pequeños o gaztetxes los precios aún se mantienen en torno a los 5-10 euros, como recuerda el músico Fermin Muguruza o los miembros del gaztetxe de Basauri.

El estallido de la burbuja financiera e inmobiliaria parece encadenar la explosión al fenómeno de los conciertos. Prácticamente todos los entrevistados ratifican el desplome del formato concierto en los últimos 3-4 años, aludiendo en muchos casos a la crisis económica.

Programadores de salas como Fever o Plateruena, el Kafe Antzokia ${ }^{5}$ de Durango, coinciden estupefactos en que les resulta extremadamente complicado calcular cuándo un concierto va a resultar mínimamente exitoso, pues cada vez depende más de factores ajenos al mismo: si llueve, hay exámenes, alguna fiesta, que la policía municipal eche a los que están haciendo botellón en alguna plaza...

Ha habido un momento en el que podíamos pagarlas y hay otro momento en el que no. [...] Sigue habiendo cosas que se pagan, más que hace 20 años, pero no hay tanto como hace cinco. Hay un momento de subida y ahora estamos en un momento de bajada...

Los chavales es que lo que sí creo que han perdido es un poco el... Hombre, a ver, tampoco es que nuestra generación estuviéramos todo el día de conciertos... Pero no van a muchos conciertos. Tampoco tienen mucha tela, claro, son conciertos de 20 euros... Nosotros yo recuerdo que íbamos a conciertos de 200 pelas... (Programadores musicales Sala Fever, entrevista personal, 08.10.2013)

Pero el fenómeno no sólo concierne a las grandes giras internacionales o a los locales más grandes (y más caros). Iker Barandiaran lo refleja también en relación a los locales más pequeños o los gaztetxes, reflexión compartida

\footnotetext{
${ }^{4}$ Squat, espacios okupados desde los 80 , autogestionados por las asambleas de jóvenes de pueblos o barrios. Algunos legalizados, e incluso reconvertidos en potentes centros culturales con acuerdo municipal. Unos más recientes, otros con una dilatada trayectoria.

${ }^{5}$ Locales surgidos desde iniciativas populares vinculadas a la lengua vasca, combinando actividades como espacios de fiesta, gastronómicos y de conciertos, lo que facilita su viabilidad económica (no exenta de subvenciones públicas).
} 
con algunos otros entrevistados vinculados al gaztetxe de Basauri, como los integrantes del grupo punk Krimen y Kastigo. La idea señalada anteriormente en torno a la pérdida de interés en los grupos nuevos o pequeños se reitera, lo que acaba por producir cierta frustración entre los programadores de los locales más pequeños y autogestionarios.

La edad de los que acuden a los conciertos también ha sido otro aspecto ampliamente señalado: por encima de los 30 años. Incluso en el caso de grupos con componentes muy jóvenes como Belako. Los más jóvenes, coinciden casi todos, se mueven por otras motivaciones y en otros formatos.

$Y$ el formato al alza que todos apuntan es el de los festivales: combina fiesta con música, y a públicos atraídos por distintos grupos, clásicos o mediáticos en muchos casos, lo que permite acumular masa crítica. Muchas veces subvencionados y con mucho público que viene de fuera.

Referencia de la música vasca desde los 80 , Fermin Muguruza subraya el plus que proporciona el formato festivalero: permite escuchar varios grupos casi por el mismo precio. Pero sobre todo, señala, constituyen "escaparates sociales", espacios privilegiados para las relaciones sociales directas, especialmente aquellos de varios días de duración y con zona de acampada. Aunque es un formato eminentemente veraniego, hay algunos que se atreven con la complicada climatología invernal vasca, como los reivindicativos Hatortxu Rock o Kalera Rock, en favor de los derechos de los presos políticos vascos.

No obstante, no deja de ser un formato también con altibajos y complicado: "Te la juegas a una" recuerdan desde la sala Fever. Algunos han ido desapareciendo. En el 2014 festivales como Azken ikasle dantza, organizado por la agrupación estudiantil de izquierda independentista Ikasle Abertzaleak, tuvo que ser suspendido; los organizadores del Kalera Rock reconocían un descenso de asistentes; al tiempo, el festival comercial Bilbao BBK Live batía todos sus registros agotando los bonos y entradas de todos los días. El tipo de festival al alza, puntualizan desde el grupo Audience, parece clónico. Iker Barandiaran subraya que, al igual que en la economía, parece que la tendencia se polariza entre eventos multitudinarios y pequeños conciertos.

Todos estos cambios, del concierto al festival, o la edad y actitud ante los conciertos, en locales grandes o autogestionarios, pone de manifiesto que junto al cambio de formato hay un cambio también en las actitudes e intereses del público.

\subsection{Las transformaciones del público: del disco a la canción (conocida)}

Otra transformación es ampliamente reseñada: el paso del disco a la canción como unidad musical de escucha referencial. La gente ahora escucha 
canciones sueltas, se ha perdido el concepto del disco como narración completa y significativa. Los cambios tecnológicos son aducidos en muchos casos como una de las causas destacadas: el formato MP3 o Spotify se han implantado socialmente como modo de escucha predominante. En este proceso, la variable edad resulta fundamental: tal y como plantea Fouce (2009), las personas más jóvenes reclaman canciones sueltas y actuales, mientras los adultos recurren a discos completos. Se rompe el discurso integral que construía el álbum, que incluía elementos adicionales como portada, fotos, texto, y que propiciaba ir más allá, incluyendo el grupo y su contexto; en su lugar encontramos fragmentos musicales aislados y heterogéneos. Lo registrado coincide con el estudio cualitativo de la Universidad de La Rioja (Andrés, 2013).

Y programadores y músicos señalan algo más al respecto, que ya hemos apuntado anteriormente: se escuchan canciones, y se demandan especialmente canciones "conocidas", famosas, que se puedan cantar. A la gente les gusta le gusta cantar juntos/as, y para eso tienen que ser canciones conocidas, nos apuntaba Zuriñe, militante independentista que regenta un pequeño bar en Bilbao: es lo más fácil. Se trata de la primacía de lo que Megías y Rodriguez (2003) denominan elementos indiferenciadores. Y si lo importante es que sean conocidas, independientemente del estilo, esto parece apuntar otro cambio en las formas de escucha: cuestiona la vigencia de las tribus, de los elementos diferenciadores, de la música como forma de identidad.

\subsubsection{La disolución de las tribus}

- Y que la gente joven ha perdido el gusto.

- Bueno, eso es una... También realmente nunca lo tuvieron...

- Ha habido momentos en que tenía mejor gusto, más bagaje cultural, a nivel musical digamos. Ahora la gente consume rápido. Y mucho motivado por las redes sociales...

- Ahora lo que hay, yo creo que la gran diferencia, es mucho acceso a la información, y una pérdida de algo que a la gente que le gustaba la música siempre ha sido, pues una de las razones, que era el investigar, conocer, compartir. Ahora todo está al alcance de todo el mundo, entonces... Y realmente las mezclas de estilos, tanto a nivel de producción, porque se han hecho así, porque la gente ya mezcla rap con electrónica, electrónica con hardcore, lo que sea. Pero a nivel de tribus urbanas sí que existe una especie de... - ¡Vacío!

- No, existe una tribu urbana que escucha todo tipo de música. Entonces, ya no están delimitados. Por lo tanto, hay alguien que te puede pedir Nirvana y Paquirrín, en la 
misma sesión, y se quedan tan contentos... Cosa que antes era posiblemente, pues, impensable, ¿no? Pero posiblemente también lo es porque ahora todo el mundo tiene acceso a todas las canciones, y realmente, bueno, de Nirvana pues solamente conocen una y de David Guetta tres y ya está. O sea, no necesitan conocer más. Posiblemente ni sepan cómo son los Nirvana, ni les hayan visto en una foto, ni sepan quién les ha producido el disco, porque nunca han tenido un disco en sus manos. Es otra fórmula, yo no creo que, que el bagaje cultural, sinceramente... (Programadores musicales Sala Fever, entrevista personal, 08.10.2013)

Este fragmento del diálogo entre dos de los gestores de la sala Fever ilustra muy bien las transformaciones en el público que venimos relatando. Dos son las ideas principales que podemos extraer, y que han aparecido también en multitud de entrevistas.

La primera es lo que podríamos denominar el cambio en la norma social de consumo musical. La disponibilidad de la música en Internet, sumado a los errores estratégicos y "avaricia" de la propia industria discográfica, han permitido una amplísima disponibilidad de acceso a la música. Y ésta se organiza con las canciones como unidad, fragmentando y diluyendo el concepto de disco y su narrativa. E incluso la propia contextualización del grupo. La canción es la unidad básica y se agota en sí misma, conociendo poco más allá del nombre del grupo.

Pero lo que ocurre con la música no es, o era, un mero acto de consumo. El etnomusicólogo y antropólogo Blacking (2006) planteaba cómo ésta expresa solidaridad grupal, al tiempo que Pablo Vila (1996) señalaba su importancia y complejidad como interpeladora de identidades. Los subculturalistas, así mismo, mostraban cómo la música podía servir a los jóvenes para construir sus identidades de forma individual y colectiva, dando expresión - resolviendo mágicamente en el plano simbólico - las contradicciones estructurales. Los postsubculturalistas no negaban esta dimensión de construcción identitaria, sino que afirmaban que ésta tenía lugar principalmente mediante procesos de consumo más individualizados, en un "supermercado" cultural global, permitiendo trascender incluso las condiciones estructurales de origen.

Lo apuntado por nuestros entrevistados va un paso más allá, y cuestiona directamente la dimensión identitaria fuerte de los procesos de consumo musical. Porque la accesibilidad a la música, en formato canción, transforma de un modo profundo los modos sociales de relación con la música. En los 80 el acceso a la música era más limitado, pero no dejaba de haberlo. Hemos mencionado esos espacios de comunicación social por los que tenía lugar una circulación e intercambios intensos: fanzines, revistas, pegatinas, 
pintadas, cómics, radios libres, las tiendas de discos, la circulación de casetes grabadas, los conciertos, el estilo... Elena López Aguirre nos hablaba de esa célula básica que era la maketa, alrededor de la cual se articulaban otros muchos agentes:

La maketa tuvo muchos padrinos: las emisoras querían emitirlas, los pintores querían diseñarlas, los pocos estudios de grabación que había rejuvenecieron con ellas, los bares las vendían, la gente las comentaba, los nuevos sellos soñaban convertirlas en disco, los promotores organizaban conciertos al aire libre y llamaban a los técnicos de sonido que empezaban a comprarse equipo, mientras las tiendas de instrumentos florecían, las distribuidoras se gestaban en torno a una mesa, un coche desvencijado y mucha determinación. (Elena López Aguirre, música y escritora, entrevista personal, 24.02.2014)

"Compartir". El acceso a la música estaba mediado e implicaba una red de relaciones sociales personales. En el mismo proceso se desarrollaba esa identidad, afectos, y gusto, conocimiento e interés musical. Un proceso rico en torno al soporte material del disco, maketa o casete grabada.

"Ahora todo está al alcance de todo el mundo", apuntan en el diálogo los programadores de la Fever. La facilidad de acceso a la música a través de Internet ha individualizado la relación con la misma. En efecto, nunca es individual, y las propias redes sociales permiten foros y grupos de afinidad. Pero el acceso a la música se ha disociado de toda una serie de relaciones sociales que antes resultaban necesarias, y que en el proceso construían afectos, identidades, estilos, relaciones sociales, personales y simbólicas: con el bar, la tienda, el soporte material, la gente que sabía o tenía discos...

El lote se ha abierto, y con ello las identidades fuertes construidas en torno a la música se diluyen. En el acceso a la música, construcciones identitarias y socialidad no pasan necesariamente por el mismo proceso social, se han autonomizado. Y ello descarga a la música de las connotaciones afectivas o identitarias con las que se revertía en tal proceso social.

La pérdida de fuerza de las tribus y la mezcla e hibridación entre estilos y estéticas son argumentos muy recurrentes en los entrevistados. El estudio de Sergio Andrés (2013) habla de eclecticismo. El vacío o una tribu híbrida y generalizada, que no deja de ser lo mismo. Y en el mismo sentido puede interpretarse también el paso del concierto al festival: del grupo en exclusiva al formato que mezcla gente y grupos, de la identificación con el grupo a una fórmula que añade más ingredientes paralelos que la música. 


\subsubsection{Música de usar y tirar}

El cambio y disociación en las formas sociales de acceso a la música la autonomiza, por tanto, de esas otras dimensiones. En gran manera, pues, la desvaloriza. Una formulación aparece de forma recurrente: la música como producto de usar y tirar, como producto más intrascendente, sin ese valor de identidad tribal anterior. Y ello facilita una mezcla, referida por casi todos, que ya no resulta dramática.

Dentro de lo que es una sesión Gramola, que nosotros le llamamos, no hay un estilo definido. Aquí se pinchan las famosas, las que vosotros queráis. Pero se pincha Nirvana también... Y los Foo Fighters... Se pincha Kiss... Y luego reggaeton...

[...] Escuchan tantas cosas, y les parece todo tan bien... Lo que sí que ha muerto es el sentimiento de pertenencia a una banda, o por gustos musicales.

[...] No lo viven como algo, como algo que crea su personalidad, y que esos artistas son un reflejo de lo que ellos realmente quieren ser, o por lo menos lo que ellos respetan en el mundo. Sino que les da igual.... Me gusta la canción ésta... Si no saben ni como son, no saben cómo es Kurt Cobain... Igual han visto un video... Yo creo que tienen una lista de reproducción en el Ipod y se acabó. Una lista de reproducción en la que van de una cosa a otra...

[...] No ven la música como algo con lo que combatir, y a lo que pertenecer. $\mathrm{O}$ no lo ven, yo creo que no lo ven tan así. O ya no tanto. O hay menos de los que lo ven así. O sea, ahora mismo es mucho más desinhibido todo. O sea, para nosotros antes la música era una seña de identidad; si te gustaba una cosa o te gustaba otra pues ya presuponías que alguien era de una manera o de otra, o por lo menos tenía unas virtudes u otras. Que es algo que cuando eres teenager marca. [...] Éstos yo creo que pasan de esa movida, o sea, lo disfrutan, pero lo disfrutan como algo de usar y tirar. (Programadores musicales Sala Fever, entrevista personal, 08.10.2013)

Adrián, uno de los responsables de la sala Fever, que es sociólogo, expresa una reflexión presente en numerosas entrevistas, desde las distintas escenas y perspectivas: la pérdida de peso, el carácter postmoderno de la relación actual con la música. Como David Hesmondhalgh (2005) ya advertía, la juventud mainstream estaría más inclinada a entrar y salir en la piscina de la música popular, que a sumergirse en ella.

Habremos de volver sobre estas reflexiones, que apuntan fenómenos de fondo. Pero nos queda por recoger otra de las ideas, que en este caso parecía generar discrepancia entre los responsables de la sala Fever, y que también ha aparecido entre muchos de los entrevistados: la pérdida de bagaje musical. 


\subsection{3. ¡Vacío! ¿Pérdida de cultura musical?}

"La gente joven ha perdido el gusto", sentenciaba contundente uno de los responsables de la sala Fever, y pionero de las sesiones de música electrónica en distintos clubs del entorno de Bilbao. Su compañero Adrián, más joven, en la treintena, y uno de los precursores en este caso de las sesiones de música alternativa en el club Bullit de Bilbao La Vieja, matizaba que quizás realmente tampoco antes lo tenían tanto. Lo que habría cambiado, como hemos desarrollado anteriormente, serían las formas sociales de acceso a la música, con lo que ello implicaba.

Con todo, la queja acerca de la falta de cultura musical ha sido recurrente entre los entrevistados. La acusación se extiende en algunos casos hacia los grandes locales, que no enseñan, y "dan a la gente lo que quiere" (Dj Mister, entrevista personal, 22.09.2013). Algo que los jóvenes del grupo Belako matizan: ¿lo que la gente quiere, o lo que la industria musical quiere? En todo caso, el papel de la industria musical en la conformación de los gustos de la audiencia ha dado pie a una larga discusión, que ha oscilado entre la perspectiva de la masa pasiva estupidizada de Adorno, o por el contrario, la de una audiencia activa productora de significados (Negus, 1996).

La sala Fever ha resultado en algunos casos referenciada como ejemplo de hacer las cosas bien por algunos, y también de ir a peor, hacia formatos más comerciales. Ellos mismos lo asumen sin grandes tapujos:

Nosotros hemos hecho una labor, que a veces no sé si ha servido para algo, pero bueno, ahí está. Nosotros nos hemos divertido mucho... Yo lo digo últimamente, nosotros hemos machacado al público a base de poner la música que se nos ponía en los cojones... La gente venía, y disfrutaba y se lo pasaba muy bien, y éramos un club mítico. [...] Nosotros éramos muy alternativos, éramos tan alternativos que nos permitíamos unos lujos que quizás no estaban adaptados realmente al gusto general. Pero claro, llega un momento en que eso se acaba. Osea, sobre todo llega la crisis y tienes.. y encima surge mucha más competencia... Y ya ni tienes la capacidad económica para seguir apostando, hay otra competencia que le da a la gente lo que quiere en bandeja. Por lo tanto tú, que hacías una labor te quedas fuera... Osea, porque aunque tu quieras hacerla es que no puedes hacerla, porque no puedes pagarla. (Programadores musicales Sala Fever, entrevista personal, 08.10.2013)

Pero también hay una importante reflexión, principalmente en boca de quienes superan los 30 , que apunta a que no se ha producido una transmisión del patrimonio musical anterior, especialmente en el caso del rock. También incluso desde el mundo de la electrónica, por parte del veterano Dj Javi de House: 
Cuando era adolescente, teníamos unas ganas de conocer estilos musicales que era digno de mención, y en estos tiempos creo que eso no existe, en parte... la culpa de las emisoras tradicionales... en parte los que somos un poco mayores que no comunicamos con la generación que viene detrás... (Javi de House, músico Dj, entrevista personal, 08.11.2013)

Xabi Erkizia introduce un factor que considera importante en la falta de transmisión y formación: la desaparición de la labor de la crítica musical.

La gente está aprendiendo, matizan especialmente desde el mundo de la electrónica. El joven Dj Iker Undersound reconoce que en su trayectoria ellos mismos también han ido aprendiendo desde una electrónica más simplista y comercial inicial; pero que tal evolución les ha acarreado críticas entre sus seguidores.

Pero las críticas, y las apelaciones a la formación, apuntan sobre todo a otro agente: los medios y en especial las emisoras musicales públicas. El aumento en influencia de los media es un fenómeno general que recogían los postsubculturalistas. Pero tal influencia no es la dominación absoluta de Adorno, como de forma perspicaz mostraban los subulturalistas o los trabajos sobre la cultura popular. La influencia está modulada por la existencia de procesos comunitarios de comunicación social, que la relativizan y modulan, permitiendo leer de forma 'oblicua' y compartida lo que viene de ellos y de lo hegemónico. $\mathrm{Y}$ en ese terreno, especialmente en el espacio social, también parecen registrarse cambios.

\subsection{El cierre espacial}

Las crecientes dificultades para realizar conciertos son ampliamente señaladas, especialmente en locales pequeños como bares. Había sido ésta en los 80 una escena potente, implicando la resignificación y apropiación de pequeñas tabernas de los centros urbanos. Siempre en precario equilibrio frente al endurecimiento de las normativas municipales en cuanto a limitaciones de horarios y ruidos.

A día de hoy, los entrevistados reconocen que los conciertos en los bares prácticamente han desaparecido. En algunos casos han sido sustituidos por Djs; pero son los menos, la lista de reproducción -a menudo reflejando la radio-fórmula- es lo que se habría generalizado.El_Txef_A, que además de Dj participa en la organización de eventos -usualmente en la calle-con la promotora Fiakun, señala que el "exceso" normativo dificulta sobremanera la realización de sesiones tanto en bares como en la calle.

El cierre espacial afectaría en algunos casos incluso a los gaztetxes, apuntan los raveros de More Jaia, también condicionados por las restricciones 
municipales. En estos casos, se sumaría otra dimensión: la progresiva diversificación en la actividad de los gaztetxes, incluyendo en su programación otros eventos como talleres orientados a diferentes edades y colectivos, había reducido el disponible para programar conciertos.

Desde el grupo Oliba Gorriak señalan otras dos dimensiones de cierre espacial: las dificultades de los grupos pequeños para acceder a espacios culturales como los Kafe Antzokia (y su política de cobro de entradas en algunos casos), así como las restricciones presupuestarias que comienzan a aplicar los Ayuntamientos en la situación de crisis económica.

Pero el espacio social tiene una dimensión más allá del espacio puramente físico al que se aplican las restricciones normativas. Posee también una dimensión simbólica y relacional. Ese conjunto que Manuel Delgado (2011) denomina "la calle" en contraposición con el concepto, a su juicio ideológicamente neoliberal, de "espacio público". La "pérdida de la vida en la calle" ha aparecido reiteradamente en varias entrevistas. Esta dimensión de debilitamiento de los espacios sociales y comunitarios de comunicación social, de avance en la individualización y privatización de los comportamientos sociales, afecta también directamente a los cambios en las formas de acceso y relación con la música y los media, más allá de la indudable influencia de los cambios tecnológicos.

\section{Closing Time: The decline of the social significance of music?}

Los cambios tecnológicos, especialmente Internet, han modificado los modos sociales de acceso a la música, basculando hacia aquellos más individuales que no requieren de redes personales de relaciones sociales. Esto es, anteriormente el acceso a la música suponía al tiempo el establecimiento de relaciones personales: con la gente de la tienda de discos, de los bares, los grupos de pares que intercambiaban discos o grabaciones... En el caso extremo, la construcción identitaria de grupos sociales en torno a la música, de las subculturas a las neotribus.

Con las nuevas tecnologías, es cierto, el intercambio sigue teniendo lugar en ellas. Pero no se trata de una relación con la misma intensidad ni dimensión afectiva que las redes de relaciones personales anteriores, cuando no resulta una exploración individual por la red. Es, en muchos casos, ese juego de picar y probar que describen los postsubculturalistas, pero cuyas consecuencias van incluso más allá.

Si las subculturas salieron tambaleándose de los 80 , cuando una de las fuentes de su "doble articulación", la cultura obrera autónoma, se desvanecía tras las derrotas políticas y los cambios estructurales del capitalismo, las (neo)tribus ahora se diluyen por la individualización y devaluación 
derivada de la lógica capitalista de los productos culturales. Y con ellas la música como elemento fuerte de construcción de identidad. Es lo que los entrevistados plantean de forma explícita como "disolución de las tribus", o de modo secundario como "pérdida de la cultura de la calle".

Una segunda idea aparece también reiteradamente: el declive del disco, y la narrativa que constituye, como célula musical básica en favor de la canción aislada, enlazada en la lista de reproducción del $i$ Pod. Los Djs del hip-hop y la electrónica trituran además, al tiempo que amplían, la propias canciones enlazándolas en el conjunto de una sesión.

Y una tercera idea adicional es apuntada: lo importante, además, es que la canción sea conocida. Así, paradójicamente, a pesar del inmenso archivo colectivo que es Internet, las facilidades para la difusión de las creaciones no revierte necesariamente en incidencia. Pareciera que siguen sonando los mismos. Y los mismos son incluso los de hace 20,30 o 40 años, o sus recreaciones actuales. La queja amarga de Simon Reynolds (2013) acerca de la "retromanía", la adicción del pop a su propio pasado, parece confirmar la desvalorización de la música. Los programadores, desde locales de ocio a contraculturales, subrayaban que para los jóvenes importa sobre todo que la canción sea conocida, no tanto el género, y que se ha "perdido" la curiosidad por explorar. $\mathrm{Y}$ "conocida" significa bien un clásico, bien un producto de moda en los media.

Una cuarta idea final hemos registrado: "lo importante es la juerga" (Joseba, organizador del festival reivindicativo Kalera Rock, entrevista personal, 26.03.2014). De la compra del disco, el movimiento -y la industria-se desplaza a los conciertos, y de éstos a los festivales, que permiten pasar por distintos grupos al modo de una lista de reproducción, y que constituyen espacios privilegiados de las relaciones sociales y personales. Las fiestas que ofrecen algo más que música, son también un formato claramente al alza frente a los conciertos. En los festivales, fiestas y discotecas, la música es el complemento de la juerga antes que elemento principal. Incluso parece estar sucediendo en los festivales reivindicativos.

En tal sentido, no importa tanto el género, o que la música (la canción) sea mala o buena, sino que sea conocida: su función es la de compartir, o en una formulación repetida en varias entrevistas, de usar y tirar. La socialidad ya no constituye un requisito de entrada, o un elemento de diferenciación como ocurría con las identidades subculturales o las neotribus. Ahora es el resultado buscado, con la música como elemento secundario, es decir, como elemento indiferenciador, que permite participar en común.

Consecuencia de estas observaciones, ésta es la tesis interpretativa que proponemos: el 'declive' lo que indicaría es un cambio en el significado social de la música, desde su carácter de elemento de construcción 
identitaria hacia una socialidad comunicativa. Para bailar y pasarlo bien, o para cantar juntos. O como un elemento más del collage comunicativo que se construye a través de las nuevas tecnologías, en la que un fragmento de canción puede ir junto a, y al mismo nivel, que cualquier otro fragmento de frase de político o personaje público. Sin una trascendencia especial. Y para todo ello lo importante es que el elemento sea conocido; no se trata de diferenciación, distinción y construcción de identidades grupales, sino de un lenguaje compartido. Así, los temas clásicos constituyen un recurso perfecto, lo mismo da que sean los Ramones o Abba. También las canciones de moda en las emisoras musicales.

Se trata de una forma de consumo musical eminentemente postmoderna y coincide parcialmente con los cambios y procesos apuntados por los postsubculturalistas: ese juego fluido de picar y mezclar, usar y tirar, con un peso importante de los media y las mercancías culturales translocales. Pero con una importante diferencia respecto a éstos/estos: la música ya no es un elemento tan importante en la construcción de proyectos de identidad, incluso aunque sean individualizados y fragmentados. Ahora la finalidad principal es simplemente la socialidad y la comunicación: un medio para compartir, cantar, bailar y divertirse juntos.

Revisión de Elena Gamazo

\section{Referencias bibliográficas}

Alonso, Luis Enrique; Conde, Fernando (1994), La Historia del consumo en España. Una aproximación a sus orígenes y primer desarrollo. Madrid: Debate.

Álvarez Monzoncillo, José María; Calvi, Juan (2015), "Music Consumption in Spain: From Analogue to Digital in the Shaping of Music", International Journal of Music Business Research, 4(2), 27-46.

Amezaga, Josu (1995), Herri kultura: Euskal Kultura eta Kultura popularrak. Leioa: UPV-EHU.

Andrés, Sergio (2013), Del cassette al Spotify: universitarios, hábitos e identidades musicales. Universidad de La Rioja.

Azkarraga, Joseba (2011), "Identitatea aro globalean. Euskal begiratu bat", in Pedro Ibarra; Mercè Cortina i Oriol (comps.), Recuperando la radicalidad: un encuentro en torno al análisis político crítico. Barcelona: Betiko Fundazioa, 113-145.

Bennett, Andy (2011), “The Post-subcultural Turn: Some Reflections 10 years on”, Journal of Youth Studies, 14(5), 493-506.

Bennett, Andy; Kahn-Harris, Keith (comps.) (2004), After Subculture. Critical Studies in Contemporary Youth Culture. London: Palgrave. 
Blacking, John (2006), ¿Hay música en el hombre? Madrid: Alianza.

Blackmann, Shane (2005), "Youth Subcultural Theory: A Critical Engagement with the Concept, its Origins and Politics, from the Chicago School to Postmodernism", Journal of Youth Studies, 8(1), 1-20.

Bourdieu, Pierre (2001), Contrafuegos 2. Por un movimiento social europeo. Barcelona: Anagrama.

Castells, Manuel (2009), Comunicación y poder. Madrid: Alianza.

Delgado, Manuel (2011), El espacio público como ideología. Madrid: La Catarata.

Feixa, Carles (1998), De jóvenes, bandas y tribus. Barcelona: Ariel.

Feixa, Carles; Nofre, Jordi (2012), “Culturas juveniles”, Sociopedia.isa, DOI:10.1177/205 684601291.

Fouce, Héctor (2009), Prácticas emergentes y nuevas tecnologías: el caso de la música digital en España. S.1.: Fundación Alternativas.

Frith, Simon (1999), "La constitución de la música rock como industria transnacional", in Luis Puig; Jenaro Talens (comps.), Las culturas del rock. Valencia: Pre-textos, 12-30.

Gabilondo, Joseba (2009), “Towards a Postmodern History of Basque Poetry: On Orality and Performance (From bertsopaperak of the Carlist Wars to Radical Rock and the Poetry of K. Uribe)", EGAN, 1-47.

García Canclini, Néstor; Cruces, Francisco; Urteaga, Maritza (comps.) (2012), Jóvenes, culturas urbanas y redes digitales. Barcelona: Editorial Ariel/ Fundación Telefónica.

Griffin, Christine Elizabeth (2010), "The Trouble with Class: Researching Youth, Class and Culture beyond the 'Birmingham School”, Journal of Youth Studies, 14(3), 245-259.

Guerra, Paula (2010), A instável leveza do rock. Génese, dinâmica e consolidação do rock alternativo em Portugal. Volumes: 1, 2 e 3. Tesis doctoral en Socíologia presentada a la Faculdade de Letras da Universidade do Porto, Portugal.

Guerra, Paula (2013), "Punk, ação e contradição em Portugal. Uma aproximação às culturas juvenis contemporâneas”, Revista Crítica de Ciências Sociais, 102, 111-134.

Hall, Stuart; Jefferson, Tony (comps.) (2006), Resistance through Rituals: Youth Subcultures in Post-War Britain. London/New York: Routledge.

Harvey, David (1998), La condición de la posmodernidad. Investigación sobre los orígenes del cambio cultural. Buenos Aires: Amorrortu Editores.

Hebdige, Dick (2004), Subcultura. El significado del estilo. Barcelona: Paidós.

Hesmondhalgh, David (2005), "Subcultures, Scens or Tribes? None of the Above", Journal of Youth Studies, 8(1), 21-40.

Jameson, Fredric (1998), Teoría de la postmodernidad. Madrid: Trotta.

Larrinaga, Josu (2014), Ttakun eta scratch: Euskal pop musikaren botsak. Tesis doctoral presentada a la Universidad del País Vasco/ Euskal Herriko Unibertsitatea (UPV-EHU).

Martín-Barbero, Jesús (1993), De los medios a las mediaciones. Comunicación, cultura y hegemonía. México: GG Mass media. 
Megías, Ignacio; Rodríguez, Elena (2003), Jóvenes entre sonidos. Hábitos, gustos y referentes musicales. Madrid: INJUVE.

Muggleton, David (2010), "From Classlessness to Clubculture. A Geneaology of Post-War British Youth Cultural Analysis”, Young, 12(2), 205-19.

Negus, Keith (1996), Popular Music in Theory: An Introduction. Cambridge: Polity Press.

Observatorio Vasco de la Cultura (2015), Informe sectorial. Industria del disco. Artes e industrial culturales 2013. Vitoria-Gasteiz: Servicio Central de Publicaciones del Gobierno Vasco.

Reynolds, Simon (2013), Retromanía. La adicción del pop a su propio pasado. Buenos Aires: Caja Negra.

Shildrick, Tracy; MacDonald, Robert (2006), "In Defence of Subculture: Young People, Leisure and Social Divisions", Journal of Youth Studies, 9(2), 125-40.

Thornton, Sarah (1995), Club Cultures: Music, Media and Subcultural Capital. Cambridge: Polity.

Vila, Pablo (1996), Identidades narrativas y música. Una primera propuesta para entender sus relaciones. Revista Transcultural de Música, 2. Consultado a 25.11.2015, em http://www.sibetrans.com/trans/articulo/288/identidades-narrativas-y-musica -una-primera-propuesta-para-entender-sus-relaciones.

Yúdice, George (2002), El recurso de la cultura. Usos de la cultura en la era global. Barcelona: Gedisa.

Zallo, Ramón (2011), "Civilización y vida social. Paradojas de la cultura digital", Revista TELOS (Cuadernos de Comunicación e Innovación), 88, Julio-Septiembre.

Artigo recebido a 20.07.2015

Aprovado para publicação a 14.12.2015

\section{Ion Andoni del Amo}

Universidad del País Vasco (UPV/EHU)

Grupo de investigación NOR

Kalebarria 7, 3. ${ }^{\circ}$ C, 48200 Durango (Bizkaia), Espanha

Contacto: ionandoni.delamo@ehu.eus

\section{Arkaitz Letamendia}

Universidad del País Vasco (UPV/EHU)

Grupo de investigación Parte Hartuz

Ibarrangoa 5, 48993 Getxo (Bizkaia), Espanha

Contacto: arkaitz.letamendia@ehu.eus 


\section{Jason Diaux}

Universidad del País Vasco (UPV/EHU)

Departamento de Sociologia II

C/Badaia 29, Esc. Izq. 4. ${ }^{\circ}$ B, 010012 Vitoria-Gasteiz (Araba), Espanha

Contacto: jason.diaux@ehu.eus

\section{The Decline in the Social Significance of Music?}

Are we witnessing a decline in the social significance of music? On one hand, technological innovations, especially digitalization, have changed social forms of accessing music, with the increasing importance of individual modes that do not require the face-to-face personal networks that had previously enabled social groups to construct their identities around music. On the other hand, the global cultural market logic of pick and mix and use and discard has had an impact on music, making it difficult to provide social meaning and identity. Based on these observations, this article proposes that the 'decline' is, in fact, a change in the social meaning of music, from an element involved in the construction of identity to an element of communicative sociality. Its main function today is that of sharing, providing a common language for sociality where neo-tribes are dissolving.

Keywords: globalization; music and identity; music consumption; sociology of music; technological evolution.

\section{Le déclin de la signification sociale de la musique?}

Sommes-nous confrontés à un déclin de la signification sociale de la musique? D'une part les innovations technologiques, en particulier la digitalisation, ont modifié les habitudes sociales d'accès à la musique, par le truchement d'une croissance progressive d'attitudes plus individualistes qui ne requièrent pas de réseaux personnels "face à face" - qui potentialisaient la construction identitaire autour de la musique. D'autre part, la logique du marché culturel mondial, d'utiliser et de jeter, a un impact sur la musique en diminuant sa capacité de générer une signification sociale et identitaire. En conclusion, nous avançons que le "déclin" est dû à un changement de la signification sociale de la musique, qui cesse d'être un élément de construction identitaire pour devenir un élément de socialité communicative. De nos jours, sa principale fonction est celle de partager, en fournissant un langage commun à la société, dans laquelle les néo-tribus se dissolvent.

Mots-clés: consommation musical; évolution technologique; globalisation; musique et identité; sociologie de la musique. 